\title{
Role of CYP4F2 as a novel biomarker regulating malignant phenotypes of liver cancer cells via the Nrf2 signaling axis
}

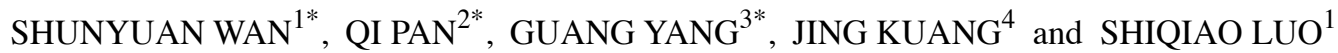 \\ ${ }^{1}$ Department of Hepatobiliary Surgery, The First Affiliated Hospital of Chongqing Medical University, Chongqing 400016; \\ ${ }^{2}$ Department of Dermatology, Chongqing Traditional Chinese Medicine Hospital, Chongqing 400011; \\ ${ }^{3}$ Department of Urology Surgery, The First Affiliated Hospital of Chongqing Medical University, Chongqing 400016; \\ ${ }^{4}$ Department of Medical Affairs, Chongqing Traditional Chinese Medicine Hospital, Chongqing 400011, P.R. China
}

Received February 12, 2020; Accepted June 23, 2020

DOI: $10.3892 / \mathrm{ol} .2020 .11874$

\begin{abstract}
Hepatocellular carcinoma (HCC) is one of the most prevalent types of cancer worldwide. The present study attempted to identify a prognostic biomarker for HCC. RNA sequencing data from the GSE63863 dataset were downloaded from the Gene Expression Omnibus database. Differentially expressed genes (DEGs) were identified based on a protein-protein interaction (PPI) network, and prognostic evaluation was subsequently conducted. Following lentiviral transfection, the migratory, proliferative and apoptotic abilities of cells were evaluated using wound healing, Cell Counting Kit-8, Transwell migration and apoptosis assays. A total of 192 DEGs were identified from 11 pairs of HCC and matched non-tumor samples. The PPI network revealed the top three modules, and eight genes were identified from these modules. The expression levels of cytochrome P450 family 4 subfamily F member 2 (CYP4F2) were downregulated in 50 HCC samples from The Cancer Genome Atlas and in the HCC Hep3B cell line. Low CYP4F2 expression was associated with a lower overall survival time. Functional studies revealed that CYP4F2 overexpression inhibited HCC cell proliferation and migration, and induced apoptosis. Furthermore, CYP4F2 overexpression repressed the expression of genes in the nuclear factor, erythroid 2 like 2 (Nrf2) signaling pathway, including Nrf2, heme oxygenase-1 and ferritin heavy chain 1 ,
\end{abstract}

Correspondence to: Dr Qi Pan, Department of Dermatology, Chongqing Traditional Chinese Medicine Hospital, 40 Daomenkou, Yuzhong, Chongqing 400011, P.R. China

E-mail: qi_pan@vip.sina.com

Dr Shiqiao Luo, Department of Hepatobiliary Surgery, The First Affiliated Hospital of Chongqing Medical University, 1 Youyi Road, Yuanjiagang, Yuzhong, Chongqing 400016, P.R. China

E-mail: shiqiaoluo@qq.com

*Contributed equally

Key words: hepatocellular carcinoma, transcriptome sequencing, prognostic biomarkers, apoptosis, Nrf2 signaling pathway while increasing NAD(P)H quinone dehydrogenase 1 expression, suggesting that CYP4F2 overexpression reversed the antioxidant response of liver cancer cells. Overall, the present findings indicated that CYP4F2 may be a potential prognostic biomarker for predicting tumorigenesis and long-term survival rates in patients with $\mathrm{HCC}$.

\section{Introduction}

Hepatocellular carcinoma (HCC) is currently the third leading cause of cancer-associated mortality globally (8.2\% in 2018) (1). The major cause of HCC is hepatitis B virus (HBV) or (HCV) infection (2), $73.4 \%$ of $\mathrm{HCC}$ cases are caused by virus (HCV) and HBV infections (3). Metabolic stress or viral infections lead to liver damage, resulting in conditions, such as chronic hepatitis and cirrhosis with deposited connective tissue, which are premalignant conditions for HCC (4). To improve the prediction of hepatocarcinogenesis, a number of studies are applying molecular profiling. In a previous study, Iizuka et al (5) evaluated gene expression in hepatitis $\mathrm{B}$ virus-positive and hepatitis $\mathrm{C}$ virus-positive $\mathrm{HCCs}$ (HBV- and HCV-HCCs) for an association with liver cirrhosis (LC), by using oligonucleotide microarray data of 45 hepatocellular carcinoma (HCC) samples. In another study, Ye et al (6) predicted hepatitis B virus-positive metastatic hepatocellular carcinomas using gene expression profiling.

To improve patient outcomes in HCC, it is important to understand the genetic features that influence the HCC phenotypes. The notable progress that has been made in next generation sequencing technology has enabled the evaluation of the interaction of multiple genes in all types of cancer (7-10). Numerous novel mutations have been identified in genes, such as janus kinase 1 (11), interferon regulatory factor 2 (12) and AT-rich interaction domain 1A (10). Genome-wide transcriptome analysis has demonstrated that the upregulation of cluster of differentiation-36 in HepG2.2.15 cells contributes to the metabolism and life-cycle of HBV (13). Weighted-gene co-expression network analysis identified several hub genes, such as spexin hormone, $\alpha$ fetoprotein and adhesion $G$ protein-coupled receptor E1 (14). Despite the identification of several HCC-associated genes, the association between gene 
expression and HCC prognosis has not yet been fully elucidated.

In the present study, a bioinformatics analysis was performed using $\mathrm{HCC}$ gene expression profiling data and The Cancer Genome Atlas (TCGA) HCC RNA sequencing (RNA-Seq) cohort. The study aimed to identify differentially expressed genes (DEGs) from these datasets in order to identify potential biomarkers by constructing protein-protein interaction (PPI) networks, and to verify and investigate these in vitro.

\section{Materials and methods}

RNA-Seq datasets of HCC. The FASTQ-formatted files of the RNA-Seq GSE63863 dataset (15) were downloaded from the Gene Expression Omnibus database (http://www.ncbi.nlm. nih.gov/geo/). The dataset was based on the Illumina 2000 platform and included 11 human primary HCC ith hepatitis B and matched adjacent non-tumor liver tissues (3-cm away from the tumor).

RNA-Seq data analysis. TopHat v2.0.9 (16) was used to align and process raw sequencing readswith UCSC hg19 (https://genome.ucsc.edu). Bowtie v0.12.8 algorithm (17) was incorporated with TopHat to perform this alignment. Subsequently, Cufflinks v2.2.1 (18) was used to analyze the aligned read files. Normalized RNA-Seq fragment counts were used to assess the abundance of transcripts. The unit of measurement was fragments per kilobase of exon per million fragments mapped (FPKM). The Bayesian inference method was used to calculate the confidence intervals for FPKM. After Cufflinks was used to assemble the read sequences, the output GTF files and the reference GTF annotation file, which was downloaded from the Ensembl database (http://www.ensembl. org/info/data/ftp/index.html) [Homo sapiens (H. sapiens); GRCh 37.55.gt], were imported into Cuffcompare v2.0.9 (http://cole-trapnell-lab.github.io/cufflinks/cuffcompare/) . A combined GTF file was produced using Cuffcompare, which was later imported into Cuffdiff v2.0.9 (http://cole-trapnell-lab. github.io/cufflinks/cuffdiff/), together with the BAM documents generated by TopHat. Subsequently, the differentially expressed genes (DEGs) from Cuffdiff were screened with the FDR $<0.05$ and fold change (FC) $>1$ criteria and visualized using the CummeRbund program v2.30.0 (https://www.bioconductor.org/packages/release/bioc/html/cummeRbund.html). All programs were used with the default parameters.

Gene Ontology (GO) and pathway enrichment analysis. Functional annotation clustering of all genes that were up- or downregulated in the 11 liver cancer and matched non-tumor samples with a false discovery rate $($ FDR $)<0.05$ was performed using the DAVID v6.8 software tool (https://david. ncifcrf.gov/) (19). Annotations from the GO resource (20) and the Kyoto Encyclopedia of Genes and Genomes (KEGG) (21) were used to measure the level of enrichment.

PPI network and module analysis. ClusterOne is a platform used to detect potential overlapping protein complexes in a High-quality INTeractomes (HINT; http://hint.yulab.org) database (22). ClusterOne (v1.0) covers 18,864 proteins from
$H$. sapiens. To assess the interactive associations between DEGs, these were mapped using ClusterOne, and the plug-in module in ClusterOne was performed for the 's' (minimum size) and 'd' (minimum cluster density) parameters. The default parameters were $\mathrm{s}=4$ and $\mathrm{d}=0.1$.

Survival analysis. OncoLnc is a tool used to interactively explore survival associations (23). Additionally, this tool allows the clinical data to be downloaded, coupled with the expression data. The tool stores the data of 8,467 patients collected from 21 cancer studies conducted by TCGA, including the RNA-Seq expression profiling data of TCGA HCC cohort $(n=360), 50$ HCC and 50 matched adjacent non-tumor liver samples were included. The 360 cases were ordered according to the relative expression of the key genes from high to low. The expression of eight key genes (RNF41, SMYD3, ABAT, GHR, SLC22A3, FCGR2B, CYP4F2 and FCGR2C) were divided into four parts, with cut-off values defining 'high' as expression above the upper quartile $(\mathrm{n}=90)$ and 'low' as expression below the lower quartile $(n=90)$. The remaining 180 cases were excluded from the analysis. The Kaplan-Meier method was used to generate the survival curves and the log-rank test was used to examine the significance. In cases where late-stage crossover of survival curves occurred, the two-stage test method was applied (24). According to this method, separate log-rank tests were used to compare the curves before and after the late-stage crossover event, generating two P-values. For each separate $\mathrm{P}$-value before and after crossover, $\mathrm{P}<0.05$ indicated significant differences in survival for that phase of the study. Expression levels of the six key genes (SMYD3, $A B A T, C Y P 4 F 2, S L C 22 A 3, R N F 41$ and GHR) in $50 \mathrm{HCC}$ and 50 matched adjacent non-tumor liver samples were compared separately, paired t-tests were used to examine the significance. The protein expression levels of the six key genes (SMYD3, ABAT, CYP4F2, SLC22A3, RNF41 and GHR) were analyzed in clinical specimens (Fig. 3C) from the Human Protein Atlas (www.proteinatlas.org) (25), all images in Fig. 3C were from the Human Protein Atlas. $\mathrm{P}<0.05$ was considered to indicate a statistically significant difference.

Cell culture. THLE-2 cells, an immortalized normal human liver cell line, as well as HepG2 and Hep3B cells derived from human liver cancer, were purchased from The Cell Bank of Type Culture Collection of the Chinese Academy of Sciences. The cells were cultured in DMEM with high glucose (HyClone; Cytiva) containing 10\% FBS (PAN Biotech GmbH) and streptomycin/penicillin $(100 \mathrm{U} / \mathrm{ml})$ at $37^{\circ} \mathrm{C}$ in a humidified incubator with $5 \% \mathrm{CO}_{2}$.

RNA extraction and reverse transcription-quantitative (RT- $q)$ $P C R$. Total RNA was extracted from the cells using RNAiso Plus kit (Takara Biotechnology Co., Ltd.) according to the manufacturer's protocol. Subsequently, the RNA was reverse transcribed into cDNA using the following temperature protocol: $37^{\circ} \mathrm{C}$ For $15 \mathrm{~min}, 85^{\circ} \mathrm{C}$ for $5 \mathrm{sec}$ and $4^{\circ} \mathrm{C}$ for $5 \mathrm{mins}$, using the PrimeScript ${ }^{\mathrm{TM}}$ RT Reagent kit containing gDNA Eraser (Takara Biotechnology Co., Ltd.). qPCR analysis was performed using SYBR Premix Ex Taq II (Takara Biotechnology Co., Ltd.) and the CFX96 Touch Real-Time PCR system (Bio-Rad Laboratories, Inc.) with the following 
thermocycling conditions: $95^{\circ} \mathrm{C}$ For $30 \mathrm{sec}, 40$ cycles of $95^{\circ} \mathrm{C}$ for $5 \mathrm{sec}$ and $60^{\circ} \mathrm{C}$ for $30 \mathrm{sec}$. The relative gene expression data were quantified using the $2^{-\Delta \Delta C q}$ method (26). GAPDH served as an internal control. The following primers were used: GAPDH forward, 5'-CTTTGGTATCGTGGAAGGACTC-3' and reverse, 5'-GTAGAGGCAGGGATGATGTTCT-3'; CYP4F2 forward, 5'-CTGAGTGCTGGTGACAAGTGGA-3' and reverse, 5'-TCATGAGGCTGATGTGCTCAA-3'; and Nrf2 forward, 5'-TACTCCCAGGTTGCCCACA-3' and reverse, 5'-CATCTACAAACGGGAATGTCTGC-3'). All reactions were performed in triplicate.

Lentivirus (LV) construction and cell transfection. The LV overexpressing CYP4F2 and the control LV were constructed and synthesized by Shanghai GenePharma Co., Ltd. Cells $\left(1 \times 10^{5}\right.$ per well) were seeded into a 12 -well plate for $24 \mathrm{~h}$, following which the medium was replaced with medium containing LV (LV5-CYP4F2 or vector; multiplicity of infection, 20) and polybrene (5 $\mu \mathrm{g} / \mathrm{ml}$ for enhanced transfection efficiency; Shanghai GenePharma Co., Ltd.). After $24 \mathrm{~h}$, the medium was substituted with DMEM supplemented with $10 \%$ FBS. The expression of green fluorescent protein (GFP) was detected to evaluate the infection efficiency using a fluorescence microscope (as transfected cells emit green fluorescence, at 100x magnification) after $72 \mathrm{~h}$. Subsequently, the medium was changed by $5 \mu \mathrm{g} / \mathrm{ml}$ puromycin complete medium and cells were cultured for $24 \mathrm{~h}$ at $37^{\circ} \mathrm{C}$ to kill the non-transfected cells. Finally, the medium was exchanged with complete medium. The aforementioned step was repeated three times. RT-qPCR and western blot analysis were performed to determine the efficiency of CYP4F2 overexpression.

Cell proliferation assay. The proliferation of cells was determined using the Cell Counting Kit-8 (CCK-8; Dojindo Molecular Technologies, Inc.) assay according to the manufacturer's protocol. Briefly, cells $\left(4 \times 10^{3}\right.$ cells/well) were plated in 96-well plates and cultured for $0,24,48,72$ and $96 \mathrm{~h}$ at $37^{\circ} \mathrm{C}$. Subsequently, CCK-8 solution was added to each well and cells were cultured for $1.5 \mathrm{~h}$ at $37^{\circ} \mathrm{C}$ in the dark. Cell proliferation was measured at $450 \mathrm{~nm}$.

Wound healing assay. The migration of Hep3B cells was determined using in vitro wound-healing assays. Briefly, cells $\left(5 \times 10^{5}\right)$ were seeded in 6 -well plates and cultured to $100 \%$ confluence. A sterile pipette tip was used to generate the wounds. Cells were washed three times with PBS to remove detached cells, treated with serum-free medium and incubated at $37^{\circ} \mathrm{C}$ for $24 \mathrm{~h}$. Images were captured at 0,24 and $48 \mathrm{~h}$ using a light microscope (magnification, x100). ImageJ v1.8.0 (National Institutes of Health) was used to measure the area of wound, and then the migration rate was calculated using the following formula: Migration rate $=\mathrm{area}_{\mathrm{x}} / \mathrm{area}_{0}$, 'area'- area of wound, ' $x$ '- time of taking images).

Transwell migration assay. The migratory ability of the Hep3B cell line was determined using a Transwell insert. Transfected and non-transfected Hep3B cells were resuspended in serum-free medium and $100 \mu \mathrm{l}$ cells $\left(4 \times 10^{4}\right)$ was added to the upper chamber, while $600 \mu 1$ medium containing 10\% FBS was added to the lower chamber. After $24 \mathrm{~h}$, cells were fixed for $15 \mathrm{~min}$ in $4 \%$ paraformaldehyde at room temperature until chamber removal. Subsequently, cells were stained for 10 min with $0.1 \%$ crystal violet at room temperature and then the inner layer of cells was carefully removed by cotton swab. Finally, three fields of view were randomly selected for each sample using a light microscope (magnification, x100) and then images were captured. ImageJ v1.8.0 was used to count the cells for each image.

Western blot analysis. Cells were harvested and lysed with the Cell lysis buffer for Western and IP (cat. no. P0013; Beyotime Institute of Biotechnology). The protein concentration was evaluated using a bicinchoninic acid kit (Beyotime Institute of Biotechnology). After separation using 8\% SDS-PAGE (10 $\mu \mathrm{g}$ total protein per well), proteins were transferred onto a polyvinylidene fluoride membrane. Subsequently, the membrane was blocked using 5\% skimmed milk and incubated overnight at $4^{\circ} \mathrm{C}$ with primary antibodies against CYP4F2 (cat. no. AF9051; 1:1,000; Affinity Biosciences), Nrf2 (cat. no. 66504-1-Ig; 1:1,000; ProteinTech Group, Inc.), NQO1(cat. no. 67240-1-Ig; 1:5,000; ProteinTech Group, Inc.), HO-1 (cat. no. 66743-1-Ig; 1:1,000; ProteinTech Group, Inc.) and FTH1 (cat. no. 10727-1-AP; 1:1000), GAPDH (cat. no. BA2913; 1:500; Wuhan Boster Biological Technology, Ltd.) as the internal reference. After three washes with TBS-Tween-20, the membrane was incubated with a secondary antibody, Mouse-IgG Rabbit antibody (cat. no. 10283-1-AP; 1:5,000; ProteinTech Group, Inc.) or Goat-IgG Rabbit Polyclonal antibody (cat. no. 10285-1-AP; 1:5,000; ProteinTech Group, Inc.), for $1 \mathrm{~h}$ at room temperature. All primary and secondary antibodies were diluted using western blotting Antibody Diluent (cat. no. AR1017; Wuhan Boster Biological Technology, Ltd.). Subsequently, the membrane was washed three times with TBS-Tween-20 and visualized using an enhanced chemiluminescence solution (Wanleibio Co., Ltd.) and quantified using a multifunctional gel imaging system (Fusion FX7 Spectra, Vilber Lourmat in the dark.

Apoptosis assay. Cell apoptosis was detected according to the manufacturer's protocol, using an Annexin V-allophycocyanin (APC) apoptosis detection kit (Sigma-Aldrich; Merck KGaA) and DAPI PB450-A. The transfected (including positive group and negative group) and untransfected cells in were resuspended in $10 \%$ phosphate buffer saline $\left(1 \times 10^{6}\right.$ cells $\left./ \mathrm{ml}\right)$. Cell mixtures containing $10 \mu 1$ Annexin V-APC and DAPI PB450-A were incubated for $15 \mathrm{~min}$ at room temperature, and then flow cytometry analysis (CytoFLEX flow cytometry system; Beckman Coulter, Inc.) was performed and datas were analysised by CytExpert 2.3.0.84; Beckman Coulter.

Statistical analysis. All experimental were repeated three times. Data were expressed as the mean \pm SD. GraphPad Prism 8 analysis software (GraphPad Software, Inc.) was used to perform the statistical analysis. One-way ANOVA were used to examine differences between two experimental groups, while mean values of $>2$ groups were compared using one-way ANOVA corrected with Bonferroni's correction. $\mathrm{P}<0.05$ was considered to indicate a statistically significant difference. 
Table I. Summary of mRNA reads in the 11 pairs of liver cancer and matched non-tumor tissues.

A, Liver cancer tissues

\begin{tabular}{lccc}
\hline Run & Left read & Right read & Overall rate, \% \\
\hline P01T & $28,297,216$ & $28,297,216$ & 99.6 \\
P02T & $30,812,501$ & $30,812,501$ & 99.4 \\
P03T & $23,547,400$ & $23,547,400$ & 99.5 \\
P04T & $36,705,394$ & $36,705,394$ & 99.7 \\
P05T & $28,488,560$ & $28,488,560$ & 99.6 \\
P06T & $28,654,873$ & $28,654,873$ & 99.6 \\
P07T & $28,909,671$ & $28,909,671$ & 99.6 \\
P08T & $21,754,053$ & $21,754,053$ & 99.4 \\
P09T & $27,695,079$ & $27,695,079$ & 99.7 \\
P10T & $23,844,185$ & $23,844,185$ & 99.6 \\
P11T & $29,781,102$ & $29,781,102$ & 99.7 \\
\hline
\end{tabular}

B, Matched non-tumor tissues

\begin{tabular}{lccc}
\hline Run & Left read & Right read & Overall rate, \% \\
\hline P01N & $27,672,329$ & $27,672,329$ & 99.5 \\
P02N & $24,241,776$ & $24,241,776$ & 99.6 \\
P03N & $21,819,135$ & $21,819,135$ & 99.6 \\
P04N & $42,363,508$ & $42,363,508$ & 99.8 \\
P05N & $28,652,601$ & $28,652,601$ & 99.6 \\
P06N & $31,060,859$ & $31,060,859$ & 99.6 \\
P07N & $31,415,753$ & $31,415,753$ & 99.7 \\
P08N & $26,931,333$ & $26,931,333$ & 99.6 \\
P09N & $30,377,104$ & $30,377,104$ & 99.7 \\
P10N & $23,039,779$ & $23,039,779$ & 99.7 \\
P11N & $27,147,987$ & $27,147,987$ & 99.7 \\
\hline
\end{tabular}

P, patient; T, tumor; N, non-tumor.

\section{Results}

Summary of the RNA-Seq data. RNA-Seq data for 11 pairs of HCC with hepatitis B and matching non-tumor liver samples were downloaded from the GSE63863 dataset (15), which resulted in an output of $\sim 250.8 \mathrm{~GB}$ of raw sequence. On average, 55.9 million raw sequencing reads were obtained following RNA-Seq, and $\sim 99.5 \%$ of the reads were aligned to the transcribed database of reference genome (Table I).

Identification of DEGs and functional annotation. A total of 22,646 genes were identified between the 11 liver cancer and matched non-tumor tissues. Among these, 192 DEGs were identified according to the Cuffdiff software with the FDR $<0.05$ and FC $>1$ criteria; among these DEGs, 109 were identified as downregulated, while 83 were identified as upregulated. The expression heatmap of the DEGs is displayed in Fig. 1. The 192 DEGs were uploaded into the DAVID online tool for the identification of GO categories.
All GO terms within FDR $<0.05$ were list in Table II. Among the biological processes, upregulated DEGs were enriched in 'daunorubicin metabolic process' and 'doxorubicin metabolic process', whereas the downregulated DEGs were enriched in 'acute-phase response'. For molecular function, upregulated DEGs were enriched in 'ketosteroid monooxygenase activity' and 'indanol dehydrogenase activity', and the downregulated DEGs were enriched in 'monooxygenase activity', 'iron ion binding' and 'oxidoreductase activity, acting on paired donors, with incorporation or reduction of molecular oxygen'. For cellular component, the downregulated DEGs were enriched in 'extracellular space', 'extracellular exosome' and 'blood microparticle'.

In addition, a total of 20 enriched pathways were identified by KEGG pathway analysis including four enriched pathways of upregulated DEGs and 16 enriched pathways of downregulated DEGs. Four KEGG pathways within FDR $<0.05$ based on downregulated DEGs was screened. The downregulated DEGs were significantly enriched in 'complement and coagulation cascades', 'retinol metabolism', 'metabolic pathways' and 'Staphylococcus aureus infection' (Table III), while there were no enriched pathways for the upregulated DEGs (FDR $>0.05$; data not shown).

Module filtering from the PPI network. To identify key genes, a PPI network (27) of the 192 DEGs was constructed using ClusterOne (22). According to the HINT database, the top three significant modules were selected (Fig. 2), from which eight DEGs were identified, including two upregulated [ring finger protein 41 (RNF41) and SET and MYND domain containing 3 (SMYD3)] and six downregulated [Fc fragment of $\mathrm{IgG}$ receptor IIc (gene/pseudogene) (FCGR2C), FCGR2B, 4-aminobutyrate aminotransferase (ABAT), growth hormone receptor (GHR), solute carrier family 22 member 3 (SLC22A3) and CYP4F2] genes.

Identification of candidate genes. The expression levels of the eight genes identified from the aforementioned modules were further analyzed in TCGA HCC cohort to determine their clinical significance (Fig. 3A). Kaplan-Meier curve analysis revealed that patients with SMYD3 upregulated expression had a significantly lower overall survival rate compared with those with SMYD3 downregulated expression $(\mathrm{P}=0.0152$ before day $2483, \mathrm{P}=0.1514$ after), and that patients with low expression levels of ABAT $(\mathrm{P}<0.0001$ before day 3,108, $\mathrm{P}=0.5924$ after), $\mathrm{CYP} 4 \mathrm{~F} 2$ ( $\mathrm{P}=0.0018$ before day $2,133, \mathrm{P}=0.5877$ after), GHR $(\mathrm{P}=0.0004)$, SLC22A3 $(\mathrm{P}=0.0054$ before day 3,108 , $\mathrm{P}=0.8864$ after $)$ and RNF41 ( $\mathrm{P}=0.9060$ before day 2,461 , $\mathrm{P}=0.0269$ after) had a significantly lower overall survival rate compared with those with high expression levels, when take the patient's 5-year survival rate was used as a reference. And RNF41 ( $\mathrm{P}=0.9060$ before day 2,461, $\mathrm{P}=0.0269$ after) had a significantly lower overall survival rate compared with those with high expression levels when the number of days is longer than 2,461 days. However, there were no significant differences in overall survival associated with FCGR2C $(\mathrm{P}=0.5230$ before day 2,111, $\mathrm{P}=0.2698$ after $)$ and FCGR2B $(\mathrm{P}=0.3377$ before day $2,111, \mathrm{P}=0.146$ after) expression levels. To determine the clinical relevance of the expression levels of these genes, the expression levels of the key genes were analyzed 
Table II. GO analysis of differentially expressed genes.

\begin{tabular}{|c|c|c|c|c|c|c|}
\hline Expression & Category & ID & Term & Count & Percentage & FDR \\
\hline \multirow[t]{4}{*}{ Upregulated } & $\mathrm{BP}$ & GO:0044597 & $\begin{array}{l}\text { Daunorubicin metabolic } \\
\text { process }\end{array}$ & 4 & 4.97 & $4.19 \times 10^{-3}$ \\
\hline & $\mathrm{BP}$ & GO:0044598 & $\begin{array}{l}\text { Doxorubicin metabolic } \\
\text { process }\end{array}$ & 4 & 4.97 & $4.19 \times 10^{-3}$ \\
\hline & MF & GO:0047086 & $\begin{array}{l}\text { Ketosteroid monooxygenase } \\
\text { activity }\end{array}$ & 3 & 3.73 & $4.61 \times 10^{-2}$ \\
\hline & MF & GO:0047718 & $\begin{array}{l}\text { Indanol dehydrogenase } \\
\text { activity }\end{array}$ & 3 & 3.73 & $4.61 \times 10^{-2}$ \\
\hline \multirow[t]{8}{*}{ Downregulated } & $\mathrm{BP}$ & GO:0006953 & Acute-phase response & 5 & 4.94 & $2.07 \times 10^{-3}$ \\
\hline & $\mathrm{CC}$ & GO:0005615 & Extracellular space & 19 & 18.75 & $5.83 \times 10^{-4}$ \\
\hline & $\mathrm{CC}$ & GO:0070062 & Extracellular exosome & 28 & 27.64 & $2.04 \times 10^{-3}$ \\
\hline & $\mathrm{CC}$ & GO:0072562 & Blood microparticle & 13 & 12.83 & $1.62 \times 10^{-12}$ \\
\hline & MF & GO:0004497 & Monooxygenase activity & 6 & 5.92 & $1.05 \times 10^{-3}$ \\
\hline & MF & GO:0005506 & Iron ion binding & 9 & 8.88 & $1.51 \times 10^{-3}$ \\
\hline & MF & GO:0016705 & $\begin{array}{l}\text { Oxidoreductase activity, acting } \\
\text { on paired donors, with } \\
\text { incorporation or reduction } \\
\text { of molecular oxygen }\end{array}$ & 6 & 5.92 & $1.05 \times 10^{-3}$ \\
\hline & MF & GO:002003 & Heme binding & 9 & 8.88 & $4.18 \times 10^{-4}$ \\
\hline
\end{tabular}

GO, Gene Ontology; FDR, false discovery rate; BP, biological process; CC, cell component; MF, molecular function.

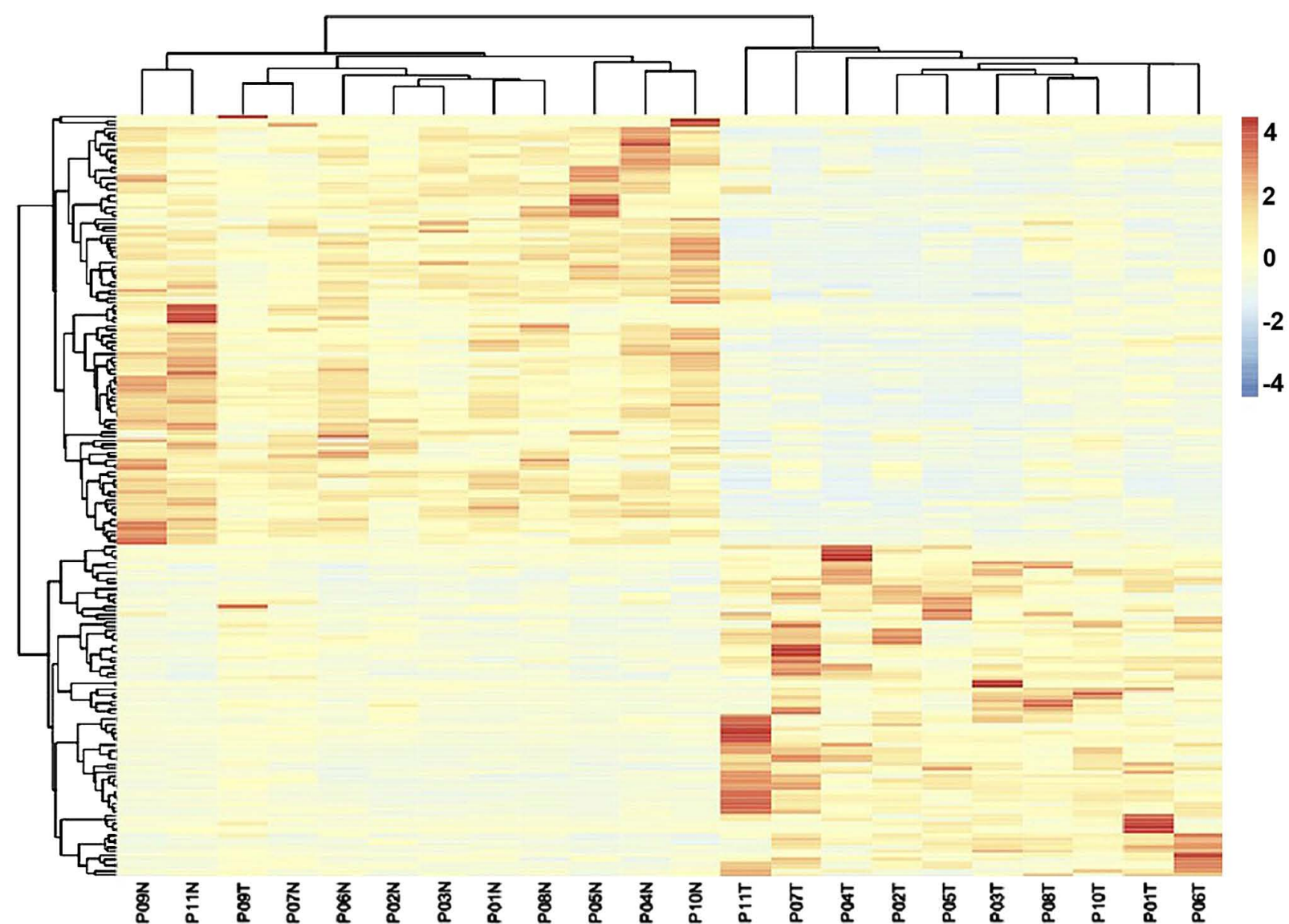

Figure 1. Distribution of up- and downregulated differentially expressed genes in 11 liver cancer and matched non-tumor tissues (fold change $>1$ and false discovery rate $<0.05$ ). Rows represent genes and columns represent samples. Red indicates genes that were upregulated, while blue indicates downregulated genes. P, patients; N, non-tumor; T, tumor. 
Table III. Kyoto Encyclopedia of Genes and Genomes pathway analysis of the downregulated differentially expressed genes.

\begin{tabular}{|c|c|c|c|c|c|}
\hline Pathway ID & Name & Count & Percent & FDR & Genes \\
\hline hsa04610 & $\begin{array}{l}\text { Complement and } \\
\text { coagulation cascades }\end{array}$ & 12 & 11.84 & $5.11 \times 10^{-9}$ & $\begin{array}{l}\text { KNG1, FGG, C9, FGA, FGB, } \\
\text { C3, C1R, SERPING1, C1S, } \\
\text { C4BPA, CFI, PLG }\end{array}$ \\
\hline hsa00830 & Retinol metabolism & 9 & 8.88 & $8.52 \times 10^{-6}$ & $\begin{array}{l}\text { CYP4A11, CYP3A5, CYP4A22, } \\
\text { CYP2C18, CYP2B6, HSD17B6, } \\
\text { UGT2B10, RDH16 }\end{array}$ \\
\hline hsa01100 & Metabolic pathways & 28 & 27.64 & $5.31 \times 10^{-5}$ & $\begin{array}{l}\text { CYP3A5, SORD, FOLH1B, } \\
\text { CYP2C18, CYP2B6, ALDOB, } \\
\text { AGXT, CYP4A22, HSD17B6, } \\
\text { HPD, ACSM2B, SUCLG2, } \\
\text { BCKDHB, ACMSD, GRHPR, } \\
\text { MAN1C1, GBA3, CYP4A11, } \\
\text { HMGCS2, ABAT, AGXT2, } \\
\text { UGT2B10, CYP4F2, RDH16, } \\
\text { PON3, UGP2 }\end{array}$ \\
\hline hsa05150 & $\begin{array}{l}\text { Staphylococcus aureus } \\
\text { infection }\end{array}$ & 8 & 7.89 & $2.62 \times 10^{-4}$ & $\begin{array}{l}\text { FGG, FCGR2B, C3, C1R, C1S, } \\
\text { FCGR2A, CFI, PLG }\end{array}$ \\
\hline
\end{tabular}

FDR, false discovery rate.

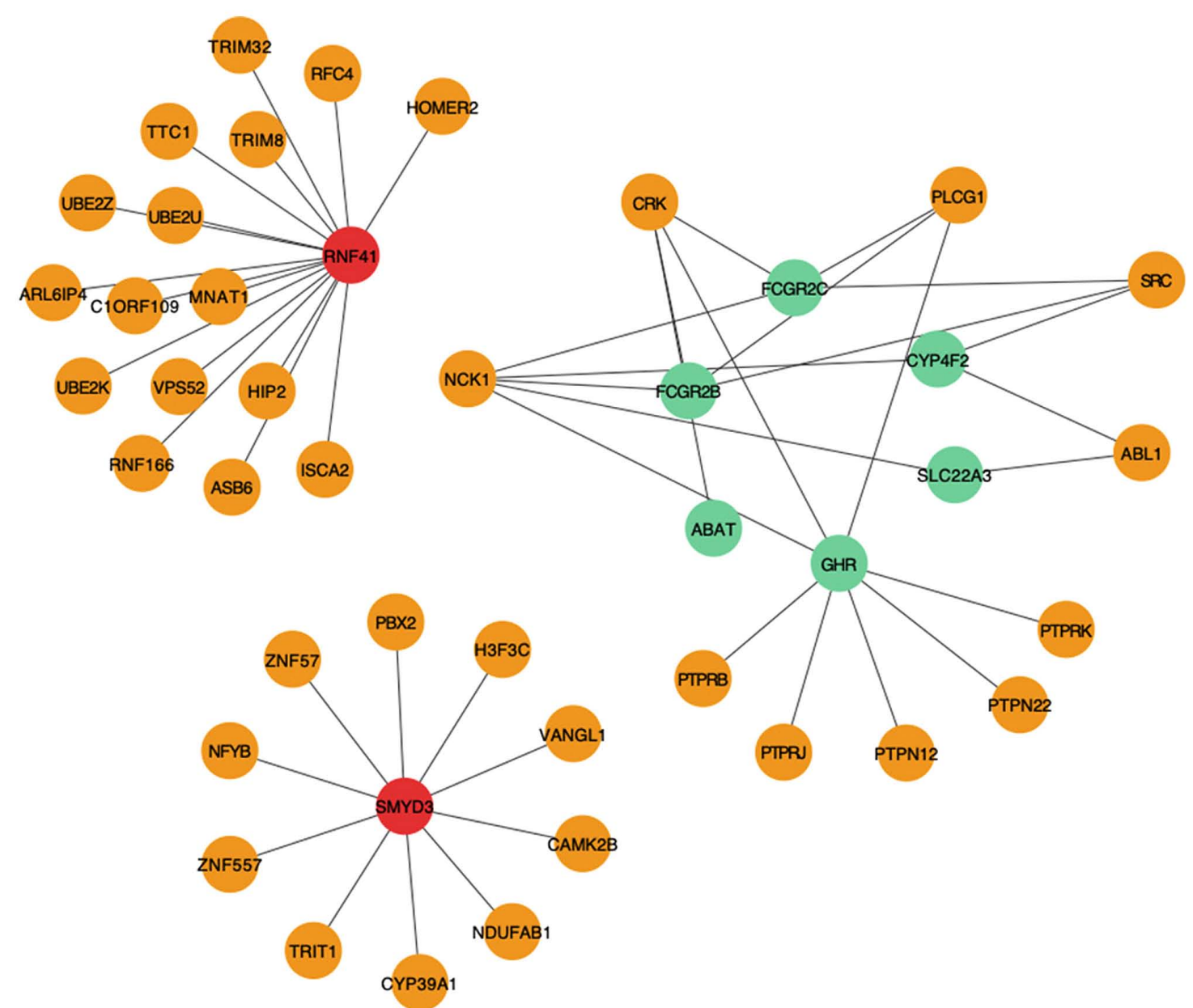

Figure 2. Top three modules from the protein-protein interaction network. Red denotes upregulated DEGs, whereas green denotes downregulated DEGs, and orange denotes molecules correlated with targets in HINT database. DEGs, differentially expressed genes. 
A

RNF41

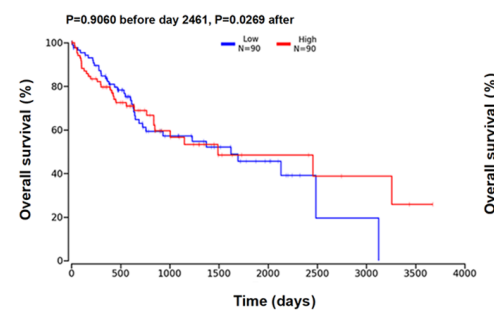

GHR
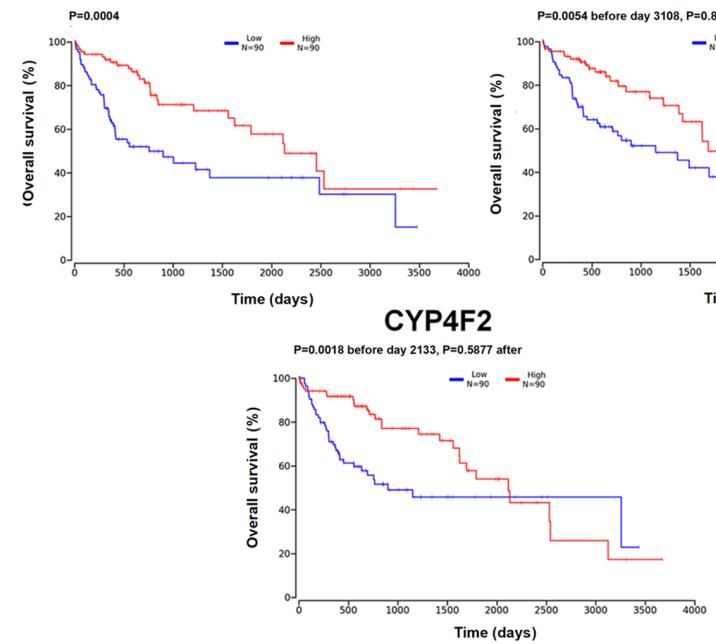

SMYD3

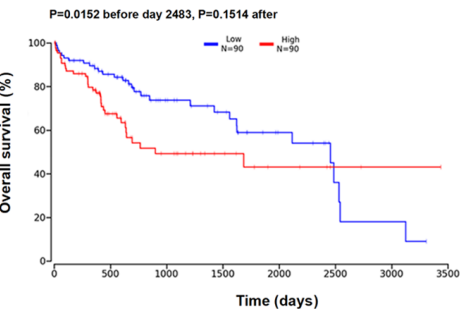

SLC22A3
ABAT

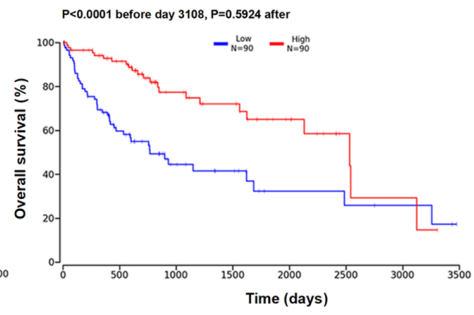

FCGR2B

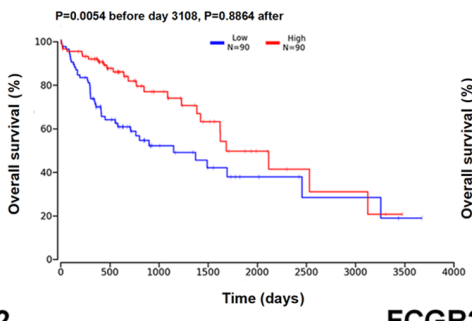

FCGR2C

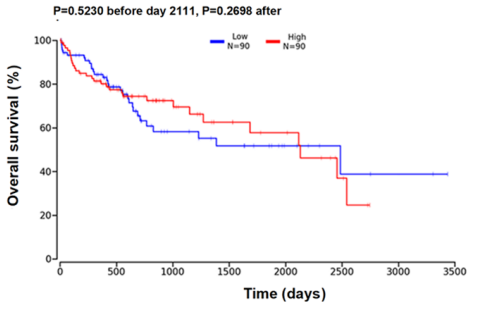

B
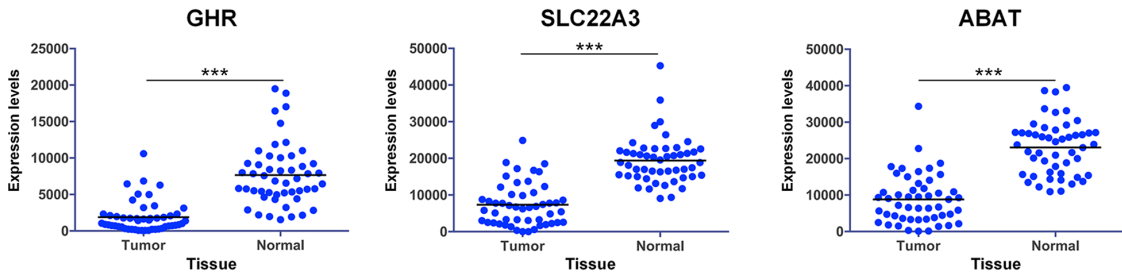

SMYD3

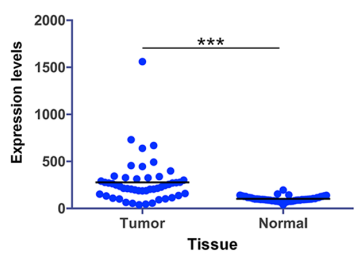

CYP4F2
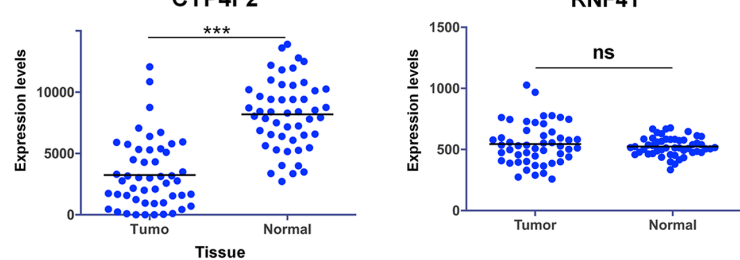

C

SMYD3
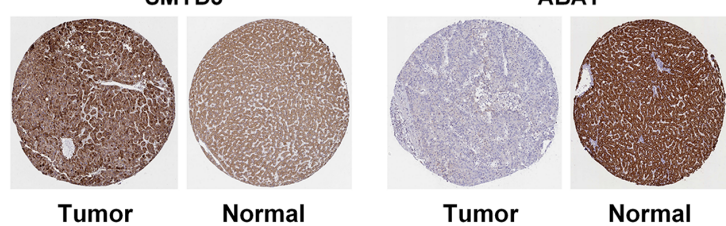

Tumor

Normal
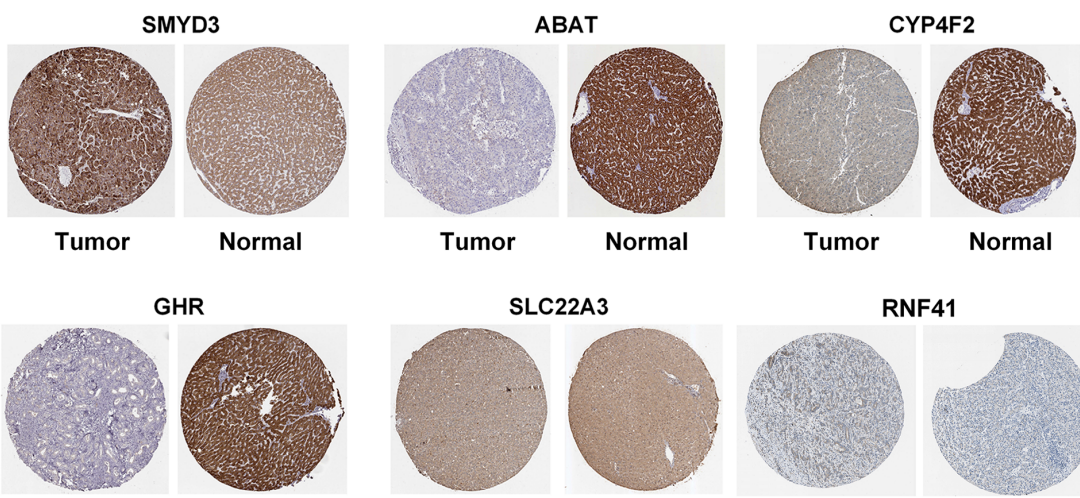

GHR

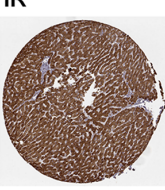

Normal

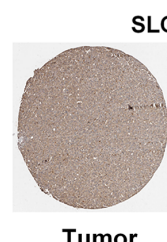

Tumor
SLC22A3

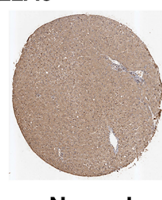

RNF41

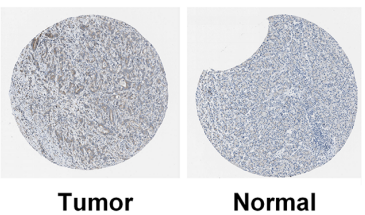

Figure 3. Kaplan-Meier overall survival analysis based on differential gene expression levels. (A) Overall survival. The red line represents the 90 individuals with high expression in the $25 \%$ upper percentile, while the blue line represents the 90 individuals with low expression in the $25 \%$ lower percentile. Two-stage test was used to examine the significance. (B) Expression levels of the six key genes in 50 pairs of The Cancer Genome Atlas hepatocellular carcinoma samples. Paired t-test was used to examine the significance, ${ }^{* * * *} \mathrm{P}<0.001$, ns not significant. (C) Protein expression in liver cancer and normal liver tissues from the Human Protein Atlas. CYP4F2, cytochrome P450 family 4 subfamily F member 2; RNF41, ring finger protein 41; SMYD3, SET and MYND domain containing 3; ABAT, 4-aminobutyrate aminotransferase; growth hormone receptor, GHR; solute carrier family 22 member 3, SLC22A3; FCGR2 Fc fragment of IgG receptor II (gene/pseudogene); FPKM, expected number of fragments per kilobase of transcript sequence per millions base pairs sequenced. 
A

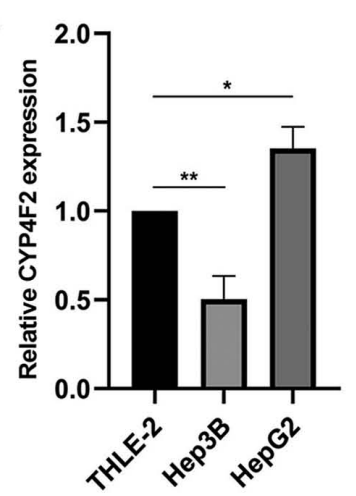

D

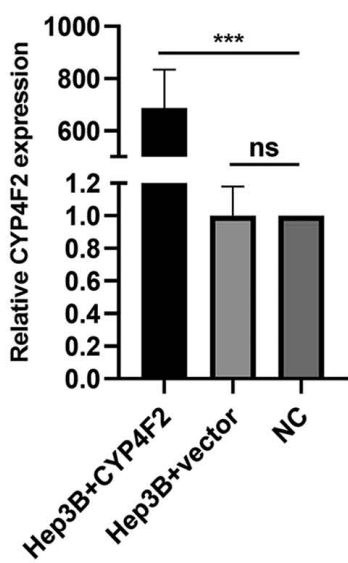

B

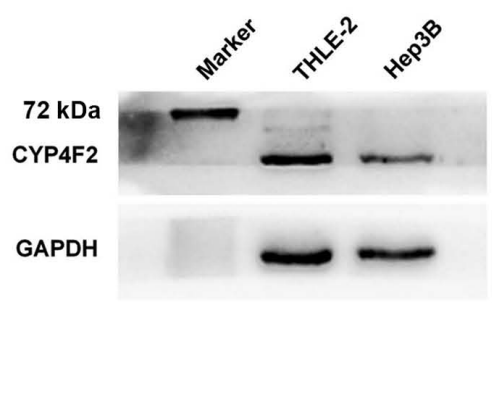

E

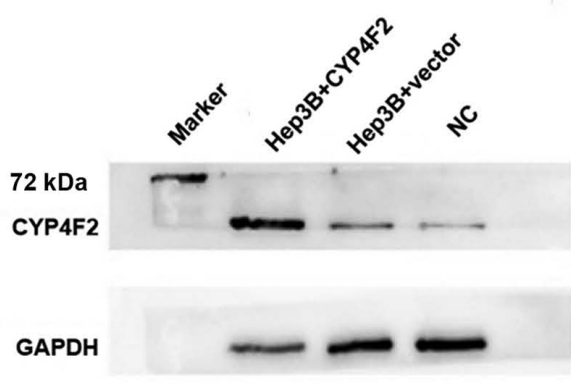

C

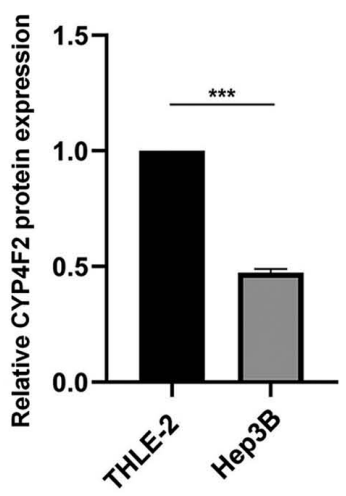

$\mathbf{F}$

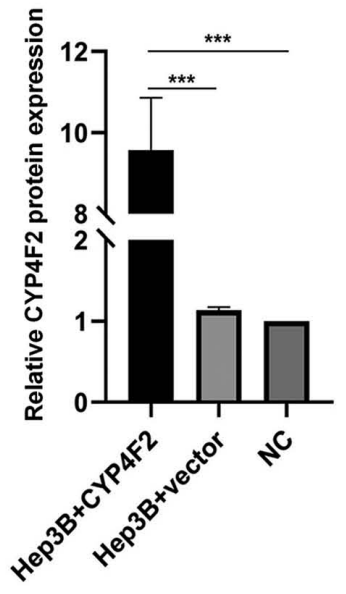

Figure 4. Expression levels of CYP4F2 in liver cancer cell lines. (A) RT-qPCR was used to determine CYP4F2 mRNA expression levels in the liver cancer Hep3B and HepG2 cell lines compared with that in the normal hepatocytes (THLE-2). (B) The CYP4F2 protein expression level in THLE-2 and Hep3B cells was determined using western blot analysis and (C) the relative protein levels were quantified. (D) RT-qPCR and (E) western blot analysis were used to determine the mRNA and protein expression levels of CYP4F2, respectively, and the protein levels were also quantified (F). Data are presented as the mean \pm SD Comparisons between multiple groups were analyzed using one-way ANOVA corrected with the Bonferroni method, while comparisons between two groups were analyzed with one-way ANOVA ${ }^{*} \mathrm{P}<0.05,{ }^{* *} \mathrm{P}<0.01$ and ${ }^{* * *} \mathrm{P}<0.001$. RT-qPCR, reverse transcription-quantitative PCR; Hep3B cells were transfected with lentivirus to overexpress CYP4F2 (Hep3B+CYP4F2), or transfected with control lentivirus was used as a negative control (Hep3B+vector), and untreated Hep3B cells served as normal control (NC).

in the specified TCGA HCC that contains both 50 HCC and 50 corresponding adjacent non-tumor liver samples. As shown in Fig. 3B, the six key genes that were significant in the aforementioned survival analysis were analyzed. The expression of GHR, SLC22A3, ABAT, CYP4F2 in tumor tissue were significantly lower than normal tissue, but SMYD3 were significantly higher, and RNF41 was no significant difference. In addition, the protein expression levels of four out of the six key genes (SMYD3, ABAT, CYP4F2, SLC22A3, RNF41 and GHR) were analyzed in clinical specimens (Fig. 3C) from the Human Protein Atlas. The results revealed that SMYD3 expression was positive in liver cancer specimens and negative in normal liver specimens, while the expression levels of ABAT, CYP4F2, SLC22A3 and GHR were negative in liver cancer specimens and positive in normal liver specimens, but there was no difference in RNF41.

CYP4F 2 overexpression regulates the proliferation, migration and apoptosis of Hep $3 B$ cells. Emerging evidence has revealed that human CYP4 enzymes serve crucial roles in liver cancer progression (28). To detect whether CYP4F2 was involved in hepatocarcinogenesis and whether it may act as a biomarker, CYP4F2 was selected for validation in subsequent functional experiments. To explore the role of CYP4F2 in $\mathrm{HCC}$, the endogenous levels of CYP4F2 were first determined in liver cancer cell lines and THLE-2 cells (an immortalized human liver cell line). CYP4F2 mRNA and protein expression were significantly downregulated in Hep3B cells compared with that in THLE-2 cells, but CYP4F2 mRNA expression was significantly upregulated in $\mathrm{HepG} 2$ cells compared with that in THLE-2 cells. (Fig. 4A-C). A recombinant lentivirus encoding CYP4F2 (Hep3B+CYP4F2) was constructed to overexpress CYP4F2, and a lentivirus expressing GFP (Hep3B+vector) served as a negative control, and untransfected Hep3B cells were used as a normal control (NC). CYP4F2 expression was significantly increased in the Hep3B cell line following transfection with the CYP4F2 lentivirus (Fig. 4D-F). CYP4F2 overexpression (Hep3B+CYP4F2) significantly reduced the proliferation of Hep3B cells compared with negative control (Hep3B+vector) and normal control (NC). as shown by the CCK-8 assays (Fig. 5A). In addition, cells in which CYP4F2 was overexpressed exhibited a lower migratory ability compared with that in cells in the control group (negative control and empty vector control) (Fig. 5B-E). The present findings indicated that CYP4F2 may be required for the metastasis of $\mathrm{Hep} 3 \mathrm{~B}$ cells. To determine the effects of CYP4F2 overexpression 
A

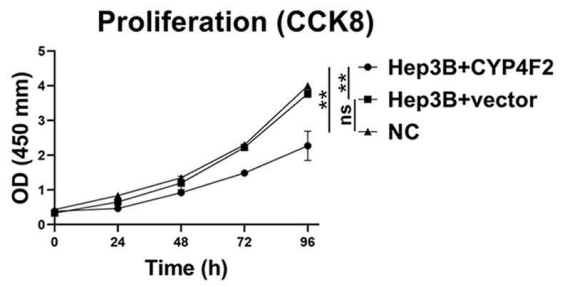

C

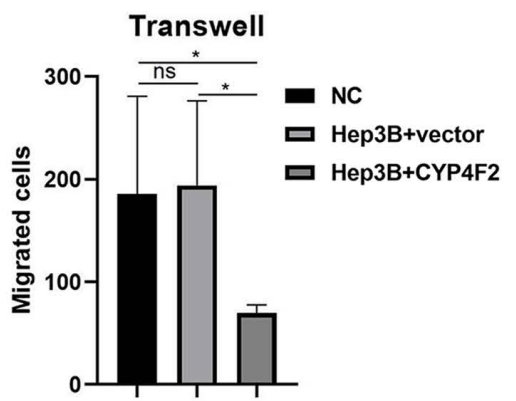

E Wound healing assay $(48 \mathrm{~h})$

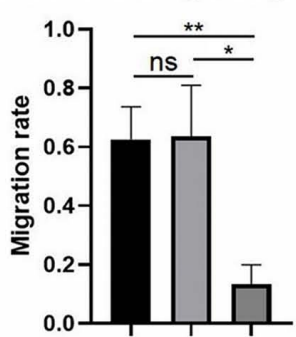

F

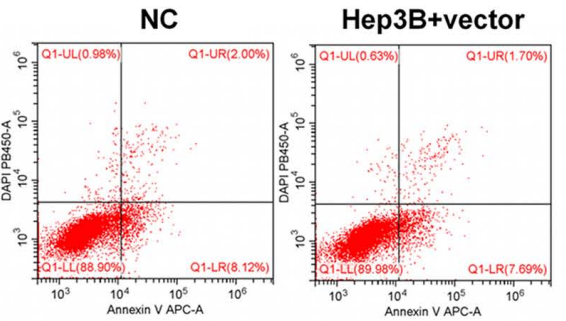

B

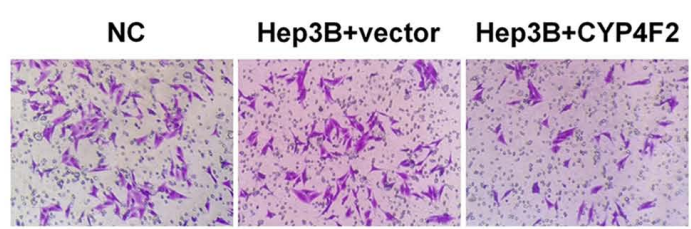

D

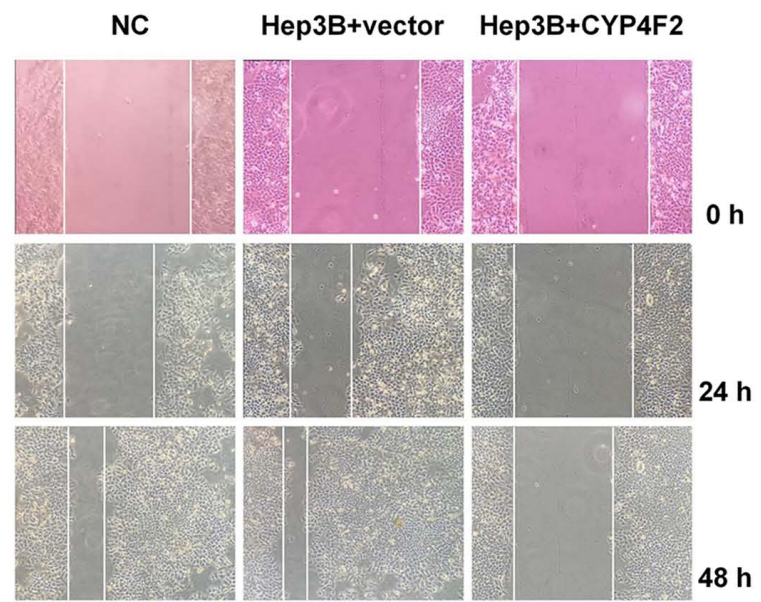

G

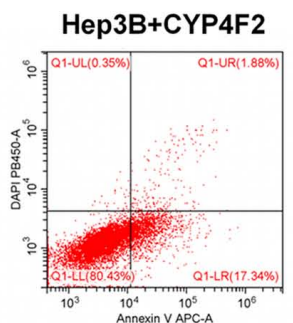

Apoptosis

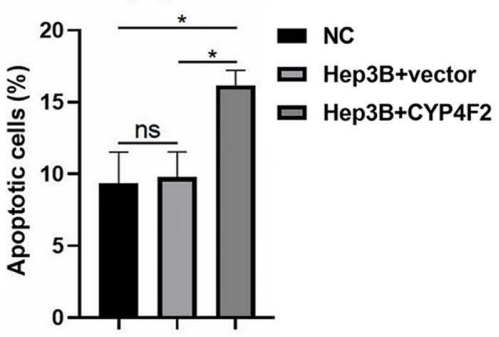

Figure 5. CYP4F2 overexpression decreases proliferation and migration, and promotes apoptosis in Hep3B cells. (A) Cell Counting Kit-8 assay was used to evaluate the proliferation of NC, Hep3B+vector and Hep3B+CYP4F2 cells. Significance of difference was detected at the 96h. (B and C) Transwell migration assay (Magnification, x100) and (D and E) wound healing assays (Magnification, $\mathrm{x} 400$ ) were used to evaluate the migratory ability of NC, Hep3B+vector and Hep3B+CYP4F2 cells. ( $F$ and G) Flow cytometry was used to measure the apoptosis rate of NC, Hep3B+vector and Hep3B+CYP4F2 cells. Data are presented as the mean $\pm \mathrm{SD}$. One-way ANOVA was used with Bonferroni correction. ${ }^{*} \mathrm{P}<0.05 ;{ }^{* * *} \mathrm{P}<0.01$; ns, not significant. Hep3B cells were transfected with lentivirus to overexpress CYP4F2 (Hep3B+CYP4F2), or transfected with control lentivirus was used as a negative control (Hep3B+vector), and untreated Hep3B cells served as normal control (NC).

on the apoptosis of Hep3B cells, apoptosis was determined using flow cytometry analysis. The apoptosis rate of Hep3B cells was significantly higher in CYP4F2-overexpressing cells compared with that in the control cells (negative control and empty vector control) (Fig. 5F and G). The present results indicated that CYP4F2 may serve a crucial role in regulating Hep3B cell apoptosis.

CYP4F2 overexpression inhibits the Nrf2 signaling pathway in liver cancer cells. The role of CYP4F2 expression in liver cancer cells was further investigated by analyzing the expression levels of Nrf2 and its downstream genes using western blot analysis (Fig. 6). The Nrf2-mediated antioxidant signaling pathway serves an essential role in the motility of cancer cells (29). As shown in Fig. 6A-G, the protein expression levels of Nrf2, heme oxygenase-1 (HO-1) and ferritin heavy chain 1 (FTH1) were significantly decreased following
CYP4F2 overexpression, while the protein levels of NAD $(\mathrm{P}) \mathrm{H}$ quinone dehydrogenase 1 (NQO1) were significantly increased compared with that in the controls, suggesting a molecular mechanism of CYP4F2 expression on cell proliferation, migration and apoptosis. The present results demonstrated that CYP4F2 overexpression reversed the malignant phenotypes of liver cancer cells via the Nrf2-mediated antioxidant signaling pathway.

\section{Discussion}

In the present study, original data were downloaded from the GSE63863 dataset, and 192 DEGs were identified between 11 HCC and matched non-tumor tissues using bioinformatic tools. The functional annotation of these DEGs presented enrichment primarily in chemical homeostasis, metabolic processes and immune responses. By constructing a PPI 
A

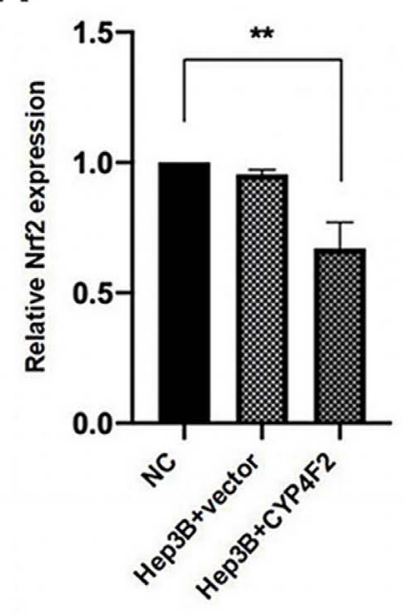

B

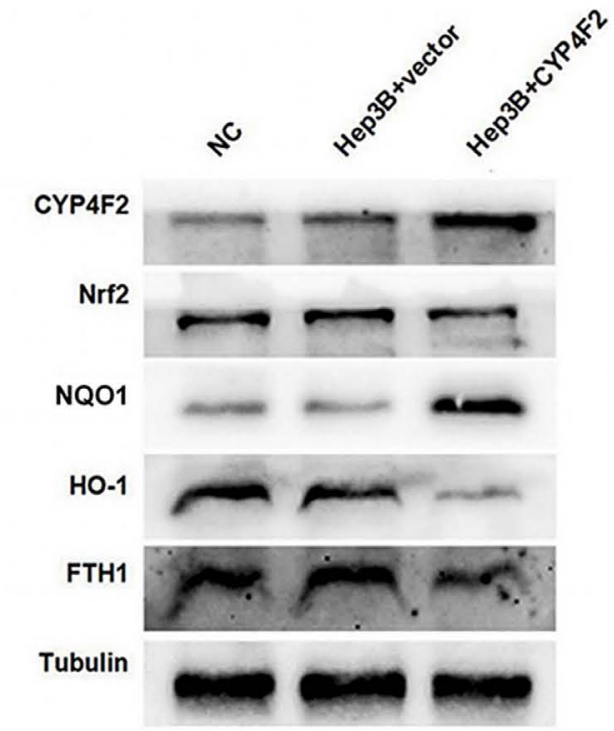

C

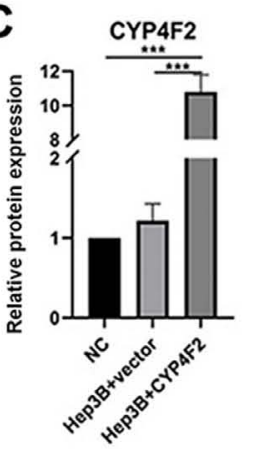

$\mathbf{F}$

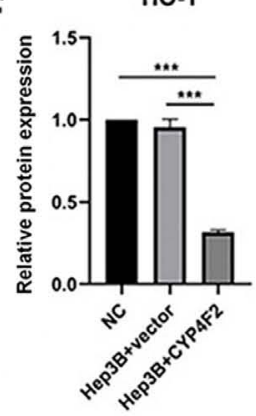

D

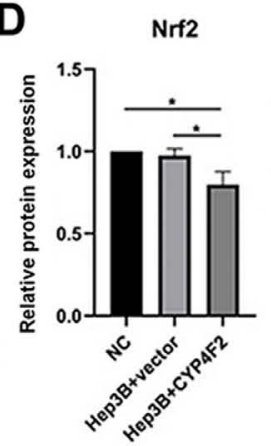

E

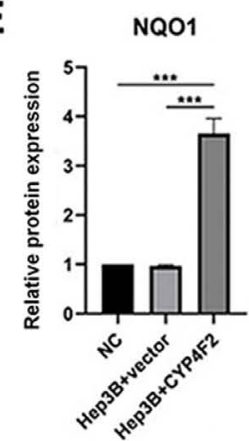

G

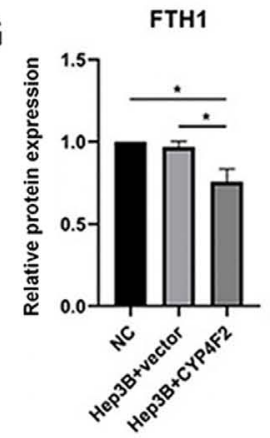

Figure 6. CYP4F2 overexpression inhibits the Nrf2 signaling pathway in liver cancer cells. (A) Reverse transcription-quantitative PCR was used to determine the Nrf2 mRNA expression levels in NC, Hep3B+vector and Hep3B+CYP4F2. (B) Western blot analysis was used to determine the protein expression levels in 5 genes and the results were quantified for CYP4F2 (C), Nrf2 (D), NQO1 (E), HO-1 (F) and FTH1 (G). Data are presented as the mean \pm SD. One-way ANOVA was used with the Bonferroni correction. ${ }^{*} \mathrm{P}<0.05 ;{ }^{* *} \mathrm{P}<0.01 ;{ }^{* * *} \mathrm{P}<0.001$. There is no significant difference between $\mathrm{NC}$ and Hep3B+vector in all figures. Hep3B cells were transfected with lentivirus to overexpress CYP4F2 (Hep3B+CYP4F2), or transfected with control lentivirus was used as a negative control (Hep3B+vector), and untreated Hep3B cells served as normal control (NC).

network, eight genes were identified in the top three modules. Among these eight genes, it was observed that differential expression of 6 genes (SMYD3, ABAT, CYP4F2, GHR, SLC22A3 and RNF41) was associated with poorer survival of patients in TCGA HCC cohort. Therefore, the present study identified potential key DEGs that may have clinical relevance, as prognostic markers for the survival of patients with HCC.

KEGG and GO pathway enrichment analyses were performed to further explore the functions of the 192 DEGs. The GO results indicated that the upregulated DEGs were primarily involved in the 'daunorubicin metabolic process' and 'doxorubicin metabolic process'. Recent studies have demonstrated that daunorubicin interacts with lipid membrane mimetic models of cancer cells in general (30) and that doxorubicin efficacy is potentiated by the DNA repair inhibitor, DT01 in preclinical animal models of HCC (31). The enriched GO terms of the downregulated DEGs were primarily involved in 'acute-phase response', 'monooxygenase activity' and 'iron ion binding'. According to a previous study, high levels of circulating interleukin- 6 were associated with the acute-phase response (32). However, fixed hepatic protein synthesis in patients with liver cancer has been found to be decreased (33). Brodie et al (34) revealed a highly significant association between liver disease and environmental factors 
(such as alcohol, high caffeine intake and smoking) on hepatic monooxygenase activity. Iron ions may serve a role in the carcinogenic process of transition metals, such as copper and nickel (35). Furthermore, the DEGs identified in the present study were significantly enriched in four KEGG pathways: 'Complement and coagulation cascades', 'retinol metabolism', 'metabolic pathways' and 'Staphylococcus aureus infection'. The glycolysis and gluconeogenesis pathways are dysregulated exclusively in HCC, whereas the coagulation and complement cascades, as well as threonine, serine and glycine metabolism, are also differentially regulated in cholangiocarcinoma (36). Notably, both hepatic stellate cells and hepatocytes are involved in retinoid metabolism (37). In addition, the severity of liver failure has been associated with the high risk of Staphylococcus aureus infection (38).

Potential key genes from the top three PPI modules, including RNF41, SMYD3, FCGR2C, FCGR2B, ABAT, GHR, SLC22A3 and CYP4F2, were identified. Among these genes, the differential expression levels of 6 genes (SMYD3, ABAT, GHR, SLC22A3, RNF41 and CYP4F2) were associated with poor survival in TCGA HCC cohort. SMYD3 promotes the development of liver cancer and is a transcriptional potentiator of multiple cancer-promoting genes, such as liver and colon cancer (39). ABAT is involved in hormone receptor-dependent regulation in breast cancer (40). The production of autocrine growth hormone 1 leads to the hyperproliferation of mammary carcinoma cells; in addition, transcriptional activation is enhanced through the GHR (41). SLC22A3 belongs to the amphiphilic solute facilitator family of integrated transmembrane proteins and has been found to be involved in the pharmacokinetics of catecholamine (42); and it was found that loss of SLC22A3 leads to increased proliferation and hepatocarcinogenesis of mice liver tumors induced by stilbene nitrosamine and phenobarbital (43).

CYP4F2 plays a critical role in the metabolism of arachidonic acid, and 20-hydroxyeicosatetraeonic acid, vitamin E and vitamin K (44). A previous study (45) implicated CYP4F2 upregulation in the poor prognosis of patients with pancreatic ductal adenocarcinoma, indicating its possible value as a biomarker capable of predicting cancer progression, as well as prognosis. However, there are limited studies on CYP4F2 in association with HCC. A previous study demonstrated that the mRNA of CPY4F2 was expressed at low levels in HCC (46) and that its expression of mRNA was altered in conjunction with the progression of HCV-associated HCC (47). However, this previous study (47) only analyzed the expression pattern of CYP4F2 in a single $\mathrm{HCV}-\mathrm{HCC}$ dataset and only predicted the diagnostic and prognostic role of CYP4F2 expression in TCGA HCC data. In addition, the function of CYP4F2 in HCC metastasis has not been elucidated. In the present study, the impact of low CYP4F2 expression in HCC specimens and cells was analyzed. Furthermore, a survival analysis on data from 180 patients with HCC obtained from TCGA database was performed to examine the association between CYP4F2 expression and prognosis. The present data revealed that low expression levels of CYP4F2 was associated with a poor prognosis compared with high expression levels. In addition, CYP4F2 overexpression inhibited the effects of HCC cell proliferation and migration, and induced apoptosis. Therefore, the present results suggested that CYP4F2 may be associated with the metastasis of liver cancer cells and that it may serve a key role in $\mathrm{HCC}$ tumorigenesis.

After determining the mRNA expression of CYP4F2 in HepG2 cells, we found that CYP4F2 mRNA expression was significantly upregulated in HepG2 cells compared with THLE-2 cells. It was reported that HepG2 originated from hepatoblastoma (HB), not HCC (48), so we hypothesized that some differences in histological origin might cause HB's CYP4F2 expression to be different from HCC. However, as the purpose of this study did not include finding the influencing factors that may cause the difference in CYP4F2 expression between $\mathrm{HB}$ and $\mathrm{HCC}$, we have not conducted relevant explorations. Therefore, HepG2 cells were not used for subsequent experiments. However, it was still interesting, we might explore this in the future study.

The Nrf2 signaling pathway serves a critical role in oxidative stress (49). Nevertheless, a recent study suggested that activation of the Nrf2 signaling pathway promoted HCC cell survival and development (50). Furthermore, the abnormal high expression of the Nrf2 signaling pathway has been detected in various malignancies, such as liver and breast cancer, and it is involved in tumor proliferation and migration $(51,52)$. In the present study, CYP4F2 overexpression notably decreased the expression levels of the Nrf2 gene, as well as those of its target genes, including HO-1 and FTH1, and increased the expression levels of NQO1, suggesting that CYP4F2 may act on the Nrf2 signaling pathway.

In conclusion, the results of the present study indicated that CYP4F2 may be an important prognostic biomarker for predicting tumorigenesis and metastasis, as well as the long-term survival rates of patients with HCC. In addition, CYP4F2 may regulate the proliferation and migration of liver cancer cells. Therefore, CYP4F2 may act as a potential biomarker for $\mathrm{HCC}$ with prognostic value.

\section{Acknowledgements}

Not applicable.

\section{Funding}

The present study was supported by the China Postdoctoral Science Found (grant no. 2019M653831XB), the Natural Science Foundation of Chongqing (grant nos. cstc2019jcyj-msxmX0095, cstc2019jcyj-msxmX0757 and CSTC2013jcyJA10105) and the National Natural Science Young Foundation of China (grant nos. 81904218, 81704091 and 30972789).

\section{Availability of data and materials}

The datasets used and/or analyzed during the current study are available from the corresponding author on reasonable request and are also available in the Gene Expression Omnibus repository, (https://www. ncbi.nlm.nih.gov/geo).

\section{Authors' contributions}

QP and SL conceived and designed the study. SW, QP, GY and JK performed the majority of the experiments and wrote 
the manuscript. All authors read and approved the manuscript and agree to be accountable for all aspects of the research in ensuring that the accuracy or integrity of any part of the work is appropriately investigated and resolved.

\section{Ethics approval and consent to participate}

Not applicable.

\section{Patient consent for publication}

Not applicable.

\section{Competing interests}

The authors declare that they have no competing interests.

\section{References}

1. Bray F, Ferlay J, Soerjomataram I, Siegel RL, Torre LA and Jemal A: Global cancer statistics 2018: GLOBOCAN estimates of incidence and mortality worldwide for 36 cancers in 185 countries. CA Cancer J Clin 68: 394-424, 2018.

2. El-Serag HB: Epidemiology of viral hepatitis and hepatocellular carcinoma. Gastroenterology 142: 1264-1273.e1, 2012.

3. Plummer M, de Martel C, Vignat J, Ferlay J, Bray F and Franceschi S: Global burden of cancers attributable to infections in 2012: A synthetic analysis. Lancet Glob Health 4: e609-616, 2016.

4. Thorgeirsson SS and Grisham JW: Molecular pathogenesis of human hepatocellular carcinoma. Nat Genet 31: 339-346, 2002 .

5. Iizuka N, Oka M, Yamada-Okabe H, Mori N, Tamesa T, Okada T, Takemoto N, Hashimoto K, Tangoku A, Hamada K, et al Differential gene expression in distinct virologic types of hepatocellular carcinoma: Association with liver cirrhosis. Oncogene 22: 3007-3014, 2003.

6. Ye QH, Qin LX, Forgues M, He P, Kim JW, Peng AC, Simon R, Li Y, Robles AI, Chen Y, et al: Predicting hepatitis B virus-positive metastatic hepatocellular carcinomas using gene expression profiling and supervised machine learning. Nat Med 9: 416-423, 2003.

7. Tateishi $\mathrm{R}$ and Omata $\mathrm{M}$; Nature Publishing Group: Hepatocellular carcinoma in 2011: Genomics in hepatocellular carcinoma - a big step forward. Nat Rev Gastroenterol Hepatol 9: 69-70, 2012.

8. Shibata T and Aburatani H: Exploration of liver cancer genomes. Nat Rev Gastroenterol Hepatol 11: 340-349, 2014.

9. Nakagawa $\mathrm{H}$ and Shibata T: Comprehensive genome sequencing of the liver cancer genome. Cancer Lett 340: 234-240, 2013.

10. Fujimoto A, Totoki Y, Abe T, Boroevich KA, Hosoda F, Nguyen HH, Aoki M, Hosono N, Kubo M, Miya F, et al Whole-genome sequencing of liver cancers identifies etiological influences on mutation patterns and recurrent mutations in chromatin regulators. Nat Genet 44: 760-764, 2012.

11. Kan Z, Zheng H, Liu X, Li S, Barber TD, Gong Z, Gao H, Hao K, Willard MD, Xu J, et al: Whole-genome sequencing identifies recurrent mutations in hepatocellular carcinoma. Genome Res 23: 1422-1433, 2013.

12. Guichard C, Amaddeo G, Imbeaud S, Ladeiro Y, Pelletier L, Maad IB, Calderaro J, Bioulac-Sage P, Letexier M, Degos F, et al: Integrated analysis of somatic mutations and focal copy-number changes identifies key genes and pathways in hepatocellular carcinoma. Nat Genet 44: 694-698, 2012.

13. Huang J, Zhao L, Yang P, Chen Z, Tang NZ, Ruan X and Chen Y: Genome-Wide Transcriptome Analysis of CD36 Overexpression in HepG2.2.15 Cells to Explore Its Regulatory Role in Metabolism and the Hepatitis B Virus Life Cycle. PLoS ONE 11: e0164787, 2016.

14. Pan Q, Long X, Song L, Zhao D, Li X, Li D, Li M, Zhou J, Tang X, Ren H, et al: Transcriptome sequencing identified hub genes for hepatocellular carcinoma by weighted-gene co-expression analysis. Oncotarget 7: 38487-38499, 2016.
15. Zhang H, Weng X, Ye J, He L, Zhou D and Liu Y: Promoter hypermethylation of TERT is associated with hepatocellular carcinoma in the Han Chinese population. Clin Res Hepatol Gastroenterol 39: 600-609, 2015.

16. Trapnell C, Pachter L and Salzberg SL: TopHat: Discovering splice junctions with RNA-Seq. Bioinformatics 25: 1105-1111, 2009.

17. Langmead B, Trapnell C, Pop M and Salzberg SL: Ultrafast and memory-efficient alignment of short DNA sequences to the human genome. Genome Biol 10: R25, 2009.

18. Trapnell C, Williams BA, Pertea G, Mortazavi A, Kwan G, van Baren MJ, Salzberg SL, Wold BJ and Pachter L: Transcript assembly and quantification by RNA-Seq reveals unannotated transcripts and isoform switching during cell differentiation. Nat Biotechnol 28: 511-515, 2010.

19. Dennis G Jr, Sherman BT, Hosack DA, Yang J, Gao W, Lane HC and Lempicki RA: DAVID: Database for Annotation, Visualization, and Integrated Discovery. Genome Biol 4: 3, 2003.

20. Ashburner M, Ball CA, Blake JA, Botstein D, Butler H, Cherry JM, Davis AP, Dolinski K, Dwight SS, Eppig JT, et al; The Gene Ontology Consortium: Gene ontology: Tool for the unification of biology. Nat Genet 25: 25-29, 2000.

21. Ogata H, Goto S, Sato K, Fujibuchi W, Bono H and Kanehisa M: KEGG: Kyoto Encyclopedia of Genes and Genomes. Nucleic Acids 27: 29-34, 1999.

22. Nepusz T, Yu H and Paccanaro A: Detecting overlapping protein complexes in protein-protein interaction networks. Nat Methods 9: 471-472, 2012.

23. Anaya J: OncoLnc: Linking TCGA survival data to mRNAs, miRNAs, and lncRNAs. PeerJ Computer Science. PeerJ Inc 2: e67, 2016

24. Qiu P and Sheng J: A two-stage procedure for comparing hazard rate functions. J R Stat Soc B 70: 191-208, 2008.

25. Uhlen M, Zhang C, Lee S, Sjöstedt E, Fagerberg L, Bidkhori G, Benfeitas R, Arif M, Liu Z, Edfors F, et al: A pathology atlas of the human cancer transcriptome. Science 357: eaan2507, 2017.

26. Livak KJ and Schmittgen TD: Analysis of relative gene expression data using real-time quantitative PCR and the 2(-Delta Delta C(T)) Method. Methods 25: 402-408, 2001.

27. Das J and Yu H: HINT: High-quality protein interactomes and their applications in understanding human disease. BMC Syst Biol 6: 92, 2012.

28. Johnson AL, Edson KZ, Totah RA and Rettie AE: Cytochrome P450 $\omega$-Hydroxylases in Inflammation and Cancer. Adv Pharmacol 74: 223-262, 2015.

29. Raghunath A, Sundarraj K, Arfuso F, Sethi G and Perumal E: Dysregulation of Nrf2 in Hepatocellular Carcinoma: Role in Cancer Progression and Chemoresistance. Cancers (Basel) 10: 481, 2018.

30. Alves AC, Ribeiro D, Horta M, Lima JLFC, Nunes C and Reis S: The daunorubicin interplay with mimetic model membranes of cancer cells: A biophysical interpretation. Biochim Biophys Acta Biomembr 1859: 941-948, 2017.

31. Herath NI, Devun F, Herbette A, Lienafa M-C, Chouteau P, Sun J-S, Dutreix M and Denys A: Potentiation of doxorubicin efficacy in hepatocellular carcinoma by the DNA repair inhibitor DT01 in preclinical models. Eur Radiol 27: 4435-4444, 2017.

32. Fearon KC, McMillan DC, Preston T, Winstanley FP, Cruickshank AM and Shenkin A: Elevated circulating interleukin- 6 is associated with an acute-phase response but reduced fixed hepatic protein synthesis in patients with cancer. Ann Surg 213: 26-31, 1991.

33. Perlmutter DH, Dinarello CA, Punsal PI and Colten HR: Cachectin/tumor necrosis factor regulates hepatic acute-phase gene expression. J Clin Invest 78: 1349-1354, 1986.

34. Brodie MJ, Boobis AR, Bulpitt CJ and Davies DS: Influence of liver disease and environmental factors on hepatic monooxygenase activity in vitro. Eur J Clin Pharmacol 20: 39-46, 1981.

35. Toyokuni S: Iron-induced carcinogenesis: The role of redox regulation. Free Radic Biol Med 20: 553-566, 1996.

36. Likhitrattanapisal S, Tipanee J and Janvilisri T: Meta-analysis of gene expression profiles identifies differential biomarkers for hepatocellular carcinoma and cholangiocarcinoma. Tumour Biol 37: 12755-12766, 2016.

37. Shirakami Y, Lee S-A, Clugston RD and Blaner WS: Hepatic metabolism of retinoids and disease associations. Biochim Biophys Acta 1821: 124-136, 2012.

38. Bert F, Bellier C, Lassel L, Lefranc V, Durand F, Belghiti J, Mentre F and Fantin B: Risk factors for Staphylococcus aureus infection in liver transplant recipients. Liver Transplant 11: 1093-1099, 2005. 
39. Sarris ME, Moulos P, Haroniti A, Giakountis A and Talianidis I: Smyd3 Is a Transcriptional Potentiator of Multiple Cancer-Promoting Genes and Required for Liver and Colon Cancer Development. Cancer Cell 29: 354-366, 2016.

40. Jansen MPHM, Sas L, Sieuwerts AM, Van Cauwenberghe C, Ramirez-Ardila D, Look M, Ruigrok-Ritstier K, Finetti P, Bertucci F, Timmermans MM, et al: Decreased expression of ABAT and STC2 hallmarks ER-positive inflammatory breast cancer and endocrine therapy resistance in advanced disease. Mol Oncol 9: 1218-1233, 2015.

41. Kaulsay KK, Zhu T, Bennett W, Lee KO and Lobie PE: The effects of autocrine human growth hormone (hGH) on human mammary carcinoma cell behavior are mediated via the hGH receptor. Endocrinology 142: 767-777, 2001.

42. Gründemann D, Schechinger B, Rappold GA and Schömig E: Molecular identification of the corticosterone-sensitive extraneuronal catecholamine transporter. Nat Neurosci 1: 349-351, 1998.

43. Vollmar J, Lautem A, Closs E, Schuppan D, Kim YO, Grimm D, Marquardt JU, Fuchs P, Straub BK, Schad A, et al: Loss of organic cation transporter 3 (Oct3) leads to enhanced proliferation and hepatocarcinogenesis. Oncotarget 8: 115667-115680, 2017.

44. Alvarellos ML, Sangkuhl K, Daneshjou R, Whirl-Carrillo M, Altman RB and Klein TE: PharmGKB summary: Very important pharmacogene information for CYP4F2. Pharmacogenet Genomics 25: 41-47, 2015.

45. Gandhi AV, Saxena S, Relles D, Sarosiek K, Kang CY, Chipitsyna G, Sendecki JA, Yeo CJ and Arafat HA: Differential expression of cytochrome P450 omega-hydroxylase isoforms and their association with clinicopathological features in pancreatic ductal adenocarcinoma. Ann Surg Oncol 20 (Suppl 3): S636-S643, 2013.
46. Eun HS, Cho SY, Lee BS, Seong I-O and Kim K-H: Profiling cytochrome P450 family 4 gene expression in human hepatocellular carcinoma. Mol Med Rep 18: 4865-4876, 2018.

47. Tsunedomi R, Iizuka N, Hamamoto $\mathrm{Y}$, Uchimura $\mathrm{S}$, Miyamoto T, Tamesa T, Okada T, Takemoto N, Takashima M, Sakamoto K, et al: Patterns of expression of cytochrome P450 genes in progression of hepatitis $\mathrm{C}$ virus-associated hepatocellular carcinoma. Int J Oncol 27: 661-667, 2005.

48. López-Terrada D, Cheung SW, Finegold MJ and Knowles BB Hep G2 is a hepatoblastoma-derived cell line. Hum Pathol 40 1512-1515, 2009.

49. Ma Q: Role of nrf2 in oxidative stress and toxicity. Annu Rev Pharmacol Toxicol 53: 401-426, 2013

50. Li R, Jia Z and Zhu H: Regulation of Nrf2 Signaling. React Oxyg Species (Apex). NIH Public Access 8: 312-322, 2019.

51. Zhang M, Zhang C, Zhang L, Yang Q, Zhou S, Wen Q and Wang $\mathrm{J}$ : Nrf2 is a potential prognostic marker and promotes proliferation and invasion in human hepatocellular carcinoma. BMC Cancer 15: 531-12, 2015.

52. Ryoo I-G, Choi B-H, Ku S-K and Kwak M-K: High CD44 expression mediates p62-associated NFE2L2/NRF2 activation in breast cancer stem cell-like cells: Implications for cancer stem cell resistance. Redox Biol 17: 246-258, 2018. 